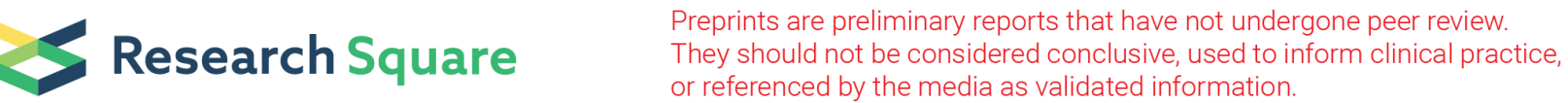

\section{Direct production of polyhydroxybutyrate and alginate from nitrogen-free waste/crude glycerol by Azotobacter vinelandii under atmospheric nitrogen conditions}

Nobuhiro Yoshida

Kyoto University

Ryuichi Takase

Kyoto University

Yoshimi Sugahara

South Incineration Plant

Yuko Nambu

Kyoto University

Wataru Hashimoto ( $\square$ hashimoto.wataru.8c@kyoto-u.ac.jp )

South Incineration Plant

\section{Research Article}

Keywords:

Posted Date: January 20th, 2022

DOI: https://doi.org/10.21203/rs.3.rs-1264094/v1

License: (c) (1) This work is licensed under a Creative Commons Attribution 4.0 International License.

Read Full License 


\section{Abstract}

While biodiesel fuel is drawing attention as an environmentally friendly fuel, use of waste/crude glycerol, a byproduct of the fuel production process, has increasingly become an essential subject to be solved. Here we show the development of a low-cost fermentation technology using an atmospheric nitrogenfixing bacterium to recycle waste/crude glycerol into functional biopolymers. Azotobacter vinelandii showed significant growth on tap water-diluted waste/crude glycerol without any pretreatment. Cell number of viable $A$. vinelandii increased over 1,000-fold under the optimal growth conditions. Most glycerol $(\sim 0.2 \%)$ in the waste/crude glycerol medium was completely depleted within $48 \mathrm{~h}$ of cultivation. The production of useful polymers, such as polyhydroxybutyrate and alginate, was also observed. Alginate productivity was increased 10 -fold by blocking polyhydroxybutyrate synthesis pathway. Although there are few examples of using waste/crude glycerol directly as a carbon source for microbial fermentation, there are no reports on the use of waste/crude glycerol without adding nitrogen source. This study indicates that it is possible to develop a technology to produce industrially useful polymers from waste/crude glycerol by energy-saving and energy-efficient fermentation using atmospheric nitrogen-fixing $A$. vinelandii.

\section{Introduction}

Biodiesel fuel (BDF) is a fatty acid methyl ester obtained from the reaction of biomass oil (triacylglycerol) with methanol in the presence of an alkaline catalyst ${ }^{1}$. In European countries, including France and Germany, practical BDF application is already underway as a national project, and it has become general among the public. BDF is also actively produced in Japan. Especially, Kyoto city with a large foodservice industry is collecting waste cooking oil from restaurants and households. BDF is also a low-pollution fuel that significantly decreases the black smoke in automobile exhaust compared to diesel oil and produces almost no sulfur oxides that cause acid rain ${ }^{1}$. Thus, BDF is attracting attention as a carbon-neutral and environmental-friendly fuel.

However, waste/crude glycerol (WG) is generated through BDF production, which corresponds to about $10 \%$ of the material, and its use has become an issue. WG contains many impurities and shows alkalinity ( $\mathrm{pH}$ 9.3). Because it is expensive to purify WG, there is an urgent need to find a way to use it ${ }^{2}$. Recently, many attempts have been made to recycle WG through microbial fermentation. Organic acids and monoand diols are produced from WG by microbes ${ }^{3-6}$. Alternatively, impurities, including lipids and methanol in WG and high pH of the WG interfere with the growth of many microorganisms. Therefore, pretreatment such as delipidation and neutralization is necessary in most cases, and there are many problems in terms of cost for practical use ${ }^{7}$.

Azotobacter vinelandii can actively use atmospheric nitrogen for nitrogen fixation $\left(\mathrm{N}_{2}+8 \mathrm{H}^{+}+8 \mathrm{e}^{-}+16\right.$ $A T P \rightarrow 2 \mathrm{NH}_{3}+\mathrm{H}_{2}+16 \mathrm{ADP}+16 \mathrm{Pi}$ ) and needs no additional nitrogen source for growth. Therefore, it is expected to decrease the cost of cultivation during fermentation. $A$. vinelandii can use various substrates, 
including glycerol, as a sole carbon source. Besides, $A$. vinelandii shows significant growth even at higher $\mathrm{pH}^{8,9}$. Another remarkable property of $A$. vinelandii is its ability to synthesize biopolymers, such as polyhydroxybutyrate (PHB) and alginate. Many studies have been reported for industrial applications since its discovery $\sim 100$ years ago ${ }^{10}$.

PHBs are polyesters of 3-hydroxybutyric acid, which accumulate in cells as a carbon and energy source for starvation or oxygen limitation ${ }^{11}$. PHBs are expected to be used as materials for biodegradable plastics that microorganisms can degrade in the environment. The substitution of petroleum-based plastics with biodegradable plastics will solve the problems of waste and environmental pollution and decrease the large amount of $\mathrm{CO}_{2}$ released during the disposal process.

Alginate is an acidic polysaccharide composed of $\beta$-D-mannuronic acid (M) and a-L-guluronic acid (G), and is manufactured by brown algae or certain bacteria (e.g., Azotobacter and Pseudomonas ${ }^{12}$ ). When water-soluble alginate forms salts with polyvalent cations such as $\mathrm{Ca}^{2+}$, the alginate solution loses the fluidity and is converted to gel forms. Alginate has many qualities, depending on the type of bound cation, $\mathrm{M} / \mathrm{G}$ ratio, and degree of polymerization and is used in various industries, such as food additive (thickening agent) and surgical thread ${ }^{13}$. Additionally, some $\mathrm{M}$ residues in bacterially derived alginate are acetylated, and alginate from $A$. vinelandii has a high frequency of $\mathrm{G}$ resides (G-block), which makes it gel easily ${ }^{14}$. Hence, alginate from $A$. vinelandii is suitable for medical applications compared to that from brown algae $\mathrm{e}^{13}$.

$\mathrm{PHB}$ and alginate have been produced from pure glycerol by $A$. vinelandii under atmospheric nitrogen condition ${ }^{15}$. This study used untreated WG as a sole carbon source for producing useful substances, such as PHB and alginate by $A$. vinelandii.

\section{Results}

A. vinelandii assimilated WG diluted with water. The growth of $A$. vinelandii wild-type was evaluated using WG medium plate with serial dilutions $(16,32,64,128$, and 256 -fold) of WG using sterile tap water. Because $A$. vinelandii secretes viscous alginate, it may be challenging to count colonies during the growth. Therefore, the growth of a strain lacking the alginate synthesis gene ( $a \lg D$ encoding GDPmannose 6-dehydrogenase) for comparison as a mutant $\Delta a l g D$ was also observed. As a result, there was little growth in wild-type and mutant $\triangle a l g D$ on 16,32 , and 64 -fold diluted medium plates. However, wildtype and mutant $\triangle a l g D$ cells grew on 128 -fold and 256 -fold diluted medium plates (Fig. $1 \mathrm{~A} \mathrm{left).} \mathrm{Both}$ showed optimal growth on the 256-diluted plate. This result demonstrated that $A$. vinelandii can assimilate WG by dilution with tap water, although impurities of WG above a certain concentration inhibited bacterial growth.

Addition of minerals to the WG medium accelerated the growth. In addition to the WG liquid medium diluted with tap water, multiple minerals commonly used for $A$. vinelandii as modified Burk (MB) medium were added to the WG medium. The growth of wild-type and mutant $\triangle a l g D$ cells was observed even at 64- 
fold dilution (Fig. 1A right). However, even in the absence of WG, a few bacterial colonies formed on the plate, suggesting that $A$. vinelandii can slightly assimilate agar as a sole carbon source. Subsequently, the time-dependent growth was evaluated using a liquid medium. Simultaneously, residual glycerol concentration in the medium was also determined. Wild-type cells grew in 256-fold diluted WG with or without minerals for $96 \mathrm{~h}$. Without adding minerals, cell numbers increased only 100 -fold at $96 \mathrm{~h}$ (Fig. 1B). The residual glycerol concentrations reduced sequentially, but they were left in the culture. Alternatively, in the WG medium supplemented with minerals (WG-MB medium), cell numbers increased more than 1000-fold at $48 \mathrm{~h}$. The glycerol concentration was depleted simultaneously (Fig. 1C). This result showed that adding minerals accelerated bacterial growth even in the liquid WG medium.

Optimized growth condition for WG assimilation. To optimize the growth condition, dilution fold, growth temperature, and shaking speed varied in the liquid WG medium. Minerals were always added in the medium. Regarding the dilution effect, 128-fold diluted WG was analyzed (Fig. 2A). However, growth was hardly detected. The optimum dilution factor was determined at 256 -fold because little growth was observed because of the lack of carbon source at dilutions higher than 256-fold. Subsequently, the incubation temperature was set at 25,30 , or $37^{\circ} \mathrm{C}$. Growth was observed at every temperature, although $30^{\circ} \mathrm{C}$ was optimal (Fig. 2B). Finally, the shaking speed at 80,120 , or $160 \mathrm{spm}$ was evaluated. The speed had little effect on cell growth (Fig. 2C). From the above results, the optimal growth conditions in WG-MB medium were at 256 -fold dilution, culture temperature of $30^{\circ} \mathrm{C}$, and shaking speed of $120 \mathrm{spm}$.

Alginate production of $A$. vinelandii from WG. Alginate production from WG was evaluated. Because alginate production competes with $\mathrm{PHB}$, the $p h b C$ gene crucial for PHB manufacture was disrupted. The resultant mutant $\triangle p h b C$ cells as well as wild-type cells were subjected to alginate production assay. Wildtype cells began to produce alginate after cultivation for $48 \mathrm{~h}$, and the alginate concentration reached about $44-\mu \mathrm{g} / \mathrm{ml}$ at $120 \mathrm{~h}$ (Fig. 3A). The conversion rate from glycerol was $24-\mathrm{mg} / \mathrm{g}-\mathrm{WG}$. This value is similar to that from pure glycerol ${ }^{15}$. Alternatively, mutant $\triangle p h b C$ cells hardly grew under the same conditions, and no alginate secretion was observed (Fig. 3B).

PHB production from WG. $A$. vinelandii cells accumulate PHB as intracellular granules and use the polymer as a carbon source and energy source during starvation ${ }^{10}$. The amount of PHB was measured using gas chromatography. Because the production of PHB and alginate compete with each other, mutant $\triangle a l g D$ cells lacking the alginate synthesis pathway were also evaluated. Wild-type and mutant $\triangle a l g D$ cells grown in WG-MB medium were harvested every $24 \mathrm{~h}$ for analyses. In both cells, PHB was detected after $48 \mathrm{~h}$ of cultivation (Fig. 4A, 4B). In wild-type, the concentration of PHB was $0.53(\mu \mathrm{g} / \mathrm{ml}$ ) at $96 \mathrm{~h}$, and cell numbers were $4.3 \times 10^{6}$ (cells $\left./ \mathrm{ml}\right)$. Alternatively, for mutant $\Delta$ algD cells, PHB was produced to be $5.22(\mu \mathrm{g} / \mathrm{ml})$, and cell numbers were $9.0 \times 10^{6}(\mathrm{cells} / \mathrm{ml})$ at $96 \mathrm{~h}$. The maximum PHB production per wild-type cell was $2.26 \times 10^{-7}(\mu \mathrm{g} / \mathrm{cell})$ at $72 \mathrm{~h}$ and reduced after $96 \mathrm{~h}$. Alternatively, PHB from mutant $\triangle a l g D$ cells increased up to $96 \mathrm{~h}$ with a maximum value of $5.75 \times 10^{-7}$ ( $\left.\mu \mathrm{g} / \mathrm{cell}\right)$ (Fig. $\left.4 \mathrm{C}\right)$. These results showed that blocking alginate synthesis pathway is important to produce a high PHB amount PHB WG. 
Morphological observation by electron microscopes. PHB is accumulated intracellularly as granules, while alginate is secreted extracellularly. These polymers are also strongly related to cyst formation, induced by an unsuitable environment for growth. To observe whether cells grown in WG accumulate PHB, wild-type cells grown in the WG-MB medium were subjected to transmission electron microscope (TEM) analysis. Most cells harvested at the stationary growth phase $(92 \mathrm{~h})$ accumulated abundant PHB granules inside the cells (Fig. 5A). Alternatively, there were a few cells in which no granules were observed, and most of them were rod-shaped (Fig. 5A). An extracellular membrane-like structure covering the cells was observed (Fig. 5B, 5B'). In the scanning electron microscope (SEM) analysis, cells in the logarithmic growth phase (48 h) were rod-shaped (Fig. 5 C), while those in the stationary growth phase (96 h) were spherical with many fibrous materials between the cells. (Fig. 5D).

\section{Discussion}

A. vinelandii cells were clarified to assimilate WG only by dilution using tap water and to produce useful substances, such as PHB and alginate. The growth was improved by the addition of minerals, and PHB production was improved by blocking the alginate synthesis pathway. Although several papers have been reported on the production of alginate by $A$. vinelandii for industrial use, most of them used sugars, such as sucrose and glucose as substrates ${ }^{14}$, and this study is, therefore, the first example of alginate production by $A$. vinelandii using "waste/crude glycerol," an industrial waste, as a substrate.

There are many PHB-producing bacteria (Burkholderia cepacia, Cupravidus necator, Pseudomonas putida, Bacillus megaterium, etc.), and many reports on PHB production using "waste/crude glycerol" as a substrate have been published ${ }^{16-19}$. To the best of our knowledge, the highest output of PHB per culture medium ( $59 \%$ cell dry weight) was reported by Freches et al. using a mixed microbial culture medium ${ }^{20}$. Although this production rate is low compared to that of Freches et al., this is the first report on PHB production without a nitrogen source. Because WG used in this study contains $45 \%$ glycerol, which is lower than that of commonly used $(\sim 70 \%)^{6}$, the production efficiency is expected to be improved using WG with fewer impurities. The concentration of WG (256-fold dilution), which was determined to be optimal, is about $0.2 \%$ in terms of glycerol concentration, which is low compared with the nutrient medium $(\sim 2 \%)^{8}$. Therefore, the amount of alginate and PHB production is limited presently. It is necessary to combine genetic manipulation and further investigation of culture conditions to enhance production efficiency.

To improve alginate productivity, genetic manipulation is an effective approach. In fact, the highest amount of alginate production from A. vinelandii was attained by Mejia et al., who used a PHB synthesisdeficient mutant and cultured it under oxygen-controlled conditions ${ }^{21}$. Additionally, our laboratory has previously reported that a highly mucoid mutant obtained by introducing random mutations has about twice the alginate production capacity compared with the wild-type ${ }^{15}$. Also, in this study, a PHB synthesisdeficient mutant $(\triangle p h b C)$ was constructed to increase alginate production. However, the cells grew poorly in WG medium and exhibited little alginate secretion (Fig. 3B). This is because the cells could be induced 
to become dormant cyst cells from the early stage of culture. It has been reported that $A$. vinelandii is susceptible to cyst induction by blocking the PHB synthesis pathway ${ }^{22}$. The growth of colonies of mutant $\triangle p h b C$ cells was much slower than that of the wild-type during colony-forming unit (CFU) measurements in this study. This suggests that a more rigorous examination of conditions is necessary when culturing PHB synthesis-deficient strains on WG medium.

PHB is actively produced in $A$. vinelandii cells during the logarithmic growth phase and is gradually consumed during the stationary growth phase or after cystification ${ }^{23}$. Wild-type and mutant $\triangle a$ alg $D$ cells produce PHB after $48 \mathrm{~h}$ in the logarithmic growth phase (Fig. 4A, 4B). Compared with the wild-type, mutant $\triangle a l g D$ cells grew well and made more PHB per cell (Fig. $4 C$ ). This may be because the carbon source used for alginate synthesis was restricted and used for growth or PHB synthesis.

In conclusion, this paper indicates the first step in developing a technology for recycling WG by energysaving and energy-efficient fermentation using atmospheric nitrogen-fixing $A$. vinelandii (Fig. 6).

\section{Methods}

Materials. WG used in this study was provided by the Kyoto Municipal Waste Edible Oil Fuel Production Facility (https://www.city.kyoto.Ig.jp/kankyo/page/0000065549.html) and comprising 45\% (w/w) glycerol, $13 \%(\mathrm{w} / \mathrm{w})$ methanol, $25 \%(\mathrm{w} / \mathrm{w})$ lipids, and other impurities. Sodium alginate (an average molecular weight: 300,000 ) from Eisenia bicyclis and agar was purchased from Nacalai Tesque (Kyoto, Japan). Restriction endonucleases and DNA-modifying enzymes were from Toyobo (Osaka, Japan) or Takara Bio (Shiga, Japan). All other analytical-grade chemicals used here were commercially available.

Bacterial strains and culture. A. vinelandii ATCC12837 wild-type, an alginate synthesis deficient mutant $(\triangle a l g D)$ with a disruption of algD gene encoding the GDP-mannose 6-dehydrogenase ${ }^{15}$, and a PHB synthesis deficient strain $(\triangle p h b C)$ by disruption of polyhydroxyalkanoate synthase subunit PhbC gene were used in this study. These bacterial cells were grown aerobically in WG-MB medium $(200-\mu \mathrm{g} / \mathrm{ml} \mathrm{NaCl}$, $50-\mu \mathrm{g} / \mathrm{ml} \mathrm{CaSO}_{4}, 200-\mu \mathrm{g} / \mathrm{ml} \mathrm{MgSO}_{4} \cdot 7 \mathrm{H}_{2} \mathrm{O}, 2.9-\mu \mathrm{g} / \mathrm{ml} \mathrm{Na}_{2} \mathrm{MoO}_{4} \cdot 2 \mathrm{H}_{2} \mathrm{O}, 27-\mu \mathrm{g} / \mathrm{ml} \mathrm{FeSO}_{4} \cdot 7 \mathrm{H}_{2} \mathrm{O}, 0.66-\mathrm{mg} / \mathrm{ml}$ $\mathrm{K}_{2} \mathrm{HPO}_{4}$ and $0.16-\mathrm{mg} / \mathrm{ml} \mathrm{KH}_{2} \mathrm{PO}_{4}$ ) containing $W \mathrm{G}$ as a sole carbon source. For the medium plate, agar was added at a concentration of $1.5 \%(\mathrm{w} / \mathrm{v})$.

Disruption of phbC gene in A. vinelandii. The $p h b C$ gene $(1.7 \mathrm{~kb})$ was amplified from the genomic DNA of A. vinelandii cells by PCR using KOD-Plus-Neo polymerase (Toyobo) and two synthetic oligonucleotide primers containing Nde『site (forward) or Xho囚site (reverse) at their 5' ends (forward, 5'GGCATATGGATCAAGCCCCCTCTTTCACAAGTTTC-3'; reverse, 5'GGCTCGAGGCCTTTCACGTAACGGCCTGGTGCTGCCTC-3') (Hokkaido System Science, Sapporo, Japan). PCR product was cloned into a Hinc》-digested pUC119 (Takara Bio) using Ligation High (Toyobo). The tetracycline-resistance gene (tet', $1.9 \mathrm{~kb}$ ) was amplified from plasmid pACYC184 (Nippon Gene, Tokyo, Japan) using two synthetic oligonucleotide primers (forward, 5'-

GGATTCTCATGTTTGACAGCTTATCATCGA-3'; reverse, 5'-CCCTACCGGACAGCGGTGCGGACTGTTGTA-3'). 
An amplified tet fragment was inserted into the middle of the $p h b C$ gene in pUC119-phbC at the Hinc $\mathbb{Z}$ restriction site using Ligation High. The resultant tet'-inserted $p h b C$ gene (phbc.:tet') fragment was amplified using two synthetic oligonucleotide primers used for $p h b C$ amplification.

A. vinelandii cells were transformed using natural transformation. The cells were grown in an MB medium (containing $1 \%$ glucose instead of WG as a carbon source) at $30^{\circ} \mathrm{C}$ until the exponential growth phase. Also, cells in $50-\mu l$ were mixed with $5-\mu l$ phbc.:tet fragment solution $(1.0-\mu \mathrm{g} / \mu \mathrm{l})$ and inoculated on the membrane filter $(0.22-\mu \mathrm{m})$ on the MB plate containing $1 \%$ glucose. After $24 \mathrm{~h}$ incubation at $30^{\circ} \mathrm{C}$, the cells on the filter were suspended in 1-ml MB buffer $\left(50-\mu \mathrm{g} / \mathrm{ml} \mathrm{CaSO}_{4}, 200-\mu \mathrm{g} / \mathrm{ml} \mathrm{MgSO}{ }_{4} \cdot 7 \mathrm{H}_{2} \mathrm{O}, 2.9-\mu \mathrm{g} / \mathrm{ml}\right.$ $\mathrm{Na}_{2} \mathrm{MoO}_{4} \cdot 2 \mathrm{H}_{2} \mathrm{O}, 27-\mu \mathrm{g} / \mathrm{ml} \mathrm{FeSO}_{4} \cdot 7 \mathrm{H}_{2} \mathrm{O}, 0.66-\mathrm{mg} / \mathrm{ml} \mathrm{K}_{2} \mathrm{HPO}_{4}$, and $0.16-\mathrm{mg} / \mathrm{ml} \mathrm{KH}_{2} \mathrm{PO}_{4}$ ). The suspension was inoculated into MB plate containing $2 \%$ sucrose and $10-\mu \mathrm{g} / \mathrm{ml}$ tetracycline hydrochloride. After three days of at $30^{\circ} \mathrm{C}$, tetracycline-resistance colonies were isolated. The disrupted $p h b C$ gene sequence was confirmed through amplification using PCR and dideoxy chain termination with an automated DNA sequencer (3130XI Genetic Analyzer, Thermo Fisher Scientific, Waltham, MA).

Glycerol assay. Glycerol concentration in the medium was assayed by the enzyme method using the F-kit glycerol (J.K. International, Tokyo, Japan) as described previously 24 .

Alginate assay. Alginate in the culture broth was obtained using the method of Sabra ${ }^{25}$. Three hundred $\mu$ l of the culture broth was mixed with $12 \mu \mathrm{l}$ of $0.5-\mathrm{M}$ EDTA and $6-\mu \mathrm{l} 5-\mathrm{M} \mathrm{NaCl}$, and alginate was separated from cells using centrifugation $\left(17,000 \times \mathrm{g}, 4^{\circ} \mathrm{C}, 5 \mathrm{~min}\right)$. Two hundred and eighty $\mu$ l of the supernatant was mixed with 900- $\mu$ cold isopropanol and incubated on ice for ten minutes. After centrifugation $\left(17,000 \times \mathrm{g}, 4^{\circ} \mathrm{C}, 5 \mathrm{~min}\right)$, the pellet was washed with cold $70 \%$ ethanol and dissolved in 1-ml sterile water at $4^{\circ} \mathrm{C}$. The resultant solution was used for the sample of alginate assay. Alginate was assayed according to the carbazole-sulfate method ${ }^{26}$. The sample was mixed with a cold solution comprising 735- $\mu$ l sulfuric acid, $17.5-\mu$ l boric acid solution (45-mM KOH and $1 \mathrm{M}$ boric acid), and $25-\mu \mathrm{l} 0.1 \%(\mathrm{w} / \mathrm{v})$ carbazole. The mixture was incubated at $55^{\circ} \mathrm{C}$ for $30 \mathrm{~min}$, and its absorbance at a wavelength of $530-\mathrm{nm}$ was measured. The standard curve was obtained using sodium alginate.

PHB assay. Here, 30-ml culture was centrifuged (4,300 $\times \mathrm{g}, 5 \mathrm{~min})$, and the pellet was resuspended in 1-ml sterile water. The suspension was freeze-dried. One $\mathrm{ml}$ chloroform containing $0.5 \%(\mathrm{w} / \mathrm{v})$ benzoic acid and $1-\mathrm{ml}$ methanol containing $3 \%$ sulfuric acid was added to the dried cells. The solution was heated at $100^{\circ} \mathrm{C}$ for $140 \mathrm{~min}$. After adding 1-ml sterile water, the solution was vortexed for one minute and centrifuged $\left(3,000 \times \mathrm{g}, 4^{\circ} \mathrm{C}, 5 \mathrm{~min}\right)$. The lower organic layer was subjected to gas chromatography GC2014 (Shimadzu, Kyoto, Japan). DB-5 column (30 m × 0.25-mm × 0.25- $\mu \mathrm{m}$, Agilent Technologies, Santa Clara, CA) was used, and helium was used as carrier gas. The temperature of the detector and injector was set at 275 and $230^{\circ} \mathrm{C}$, respectively. The oven temperature was raised from $60^{\circ} \mathrm{C}-230^{\circ} \mathrm{C}$ at a rate of $8^{\circ} \mathrm{C} /$ min during analysis. As a standard, [(R)-3-hydroxybutyrate] (Sigma, St. Louis, MO) was used.

TEM Analysis. TEM analysis was conducted in Tokai Electron Microscopy Analysis Co. (Nagoya, Japan). Thirty $\mathrm{ml}$ of $A$. vinelandii culture grown in WG-MB medium for $92 \mathrm{~h}$ was centrifuged $(4,300 \times \mathrm{g}, 5 \mathrm{~min})$ and 
the pellet was resuspended in 5-ml saline. For prefixation, the suspension was mixed with an equal volume of fixation solution $\mathrm{A}$ [ $2 \%$ paraformaldehyde, $2 \%$ glutaraldehyde, and $0.1-\mathrm{M}$ potassium phosphate buffer $(\mathrm{pH} 7.4)]$ followed by incubation at $4^{\circ} \mathrm{C}$ for $60 \mathrm{~min}$. The suspension was centrifuged $(4,300 \times \mathrm{g}$, $4^{\circ} \mathrm{C}, 5 \mathrm{~min}$ ) and the pellet was suspended in fixation solution $\mathrm{B}[2 \%$ osmium tetroxide and $0.1-\mathrm{M}$ potassium phosphate buffer $(\mathrm{pH} 7.4)$ ] followed by incubation at $4^{\circ} \mathrm{C}$ for $24 \mathrm{~h}$. The cells were centrifuged to remove the fixation solution, washed with 2-[4-(2-hydroxyethyl)-1-piperazinyl]ethanesulfonic acid (HEPES) buffer, and treated with HEPES buffer containing $2 \%$ osmium tetroxide for postfixation. The cells were then dehydrated by increasing the ethanol concentration in $30,50,70,90$, and $100 \%$ steps. The solvent was displaced by treatment with propylene oxide, and the Quetol-812 resin (Nisshin EM, Tokyo, Japan) was added to make the resin polymerized at $60^{\circ} \mathrm{C}$ for two days. Ultrathin sections of $65-70-\mathrm{nm}$ thickness were prepared from cells using a 2088 ULTROTOME V (LBK) diamond knife. Subsequently, the cells were stained using $2 \%$ uranyl acetate and lead, and the cell section structures were observed using electron microscopy (JEM-1200EX; 80 kV, JEOL, Tokyo, Japan).

SEM analysis. Here, 5-ml culture medium was mixed with an equal volume of $4 \%$ paraformaldehyde and incubated for two hours at $4^{\circ} \mathrm{C}$ to prefixation. The mixture was centrifuged $\left(17,000 \times \mathrm{g}, 4^{\circ} \mathrm{C}, 5 \mathrm{~min}\right)$, and the precipitates were washed with sterile water thrice $\left(4^{\circ} \mathrm{C}, 30 \mathrm{~min}\right)$. One $\mathrm{ml}$ of $1 \%$ osmium oxide was added and mixed, followed by incubation at $4^{\circ} \mathrm{C}$ for two hours for postfixation. The solution was removed using centrifugation $\left(17,000 \times \mathrm{g}, 4^{\circ} \mathrm{C}, 5 \mathrm{~min}\right)$ and washed with sterile water at $4^{\circ} \mathrm{C}$ for two hours. Additionally, dehydration was performed by increasing the ethanol concentration in $50,70,90$, and $100 \%$ steps. After centrifugation, the pellet was treated with $t$-butyl alcohol for 30 min twice at room temperature. The pellet, after centrifugation, was suspended in a minimal amount of $t$-butyl alcohol and frozen at $4^{\circ} \mathrm{C}$. The frozen samples were subjected to decreased pressure drying and completely dried. The obtained samples were coated with platinum-palladium and observed using scanning electron microscopy (Hitachi SU8230, Hitachi, Tokyo, Japan).

\section{Declarations}

\section{Acknowledgments}

This work was supported in part by Grant-in-Aid for Challenging Research (Pioneering) from the Japan Society for the Promotion of Science (to W. H.). The authors would like to thank Enago (www.enago.com) for the English language review.

\section{Author contributions}

W. H. designed the study. N. Y. and Y. N. performed the experiments. N. Y., R. T., Y. S., Y. N., and W. H. analyzed the data. N. Y., R. T., and W. H. wrote the manuscript.

\section{Competing interests}

The authors declare no competing interests. 


\section{References}

1. Mathew, G. M. et al. Recent advances in biodiesel production: Challenges and solutions. Sci. Total Environ. 794, 148751 (2021).

2. da Silva, G. P., Mack, M. \& Contiero, J. Glycerol: A promising and abundant carbon source for industrial microbiology. Biotechnol. Adv. 27, 30-39 (2009).

3. Vivek, N., Pandey, A. \& Binod, P. Biological valorization of pure and crude glycerol into 1,3-propanediol using a novel isolate Lactobacillus brevis N1E9.3.3. Bioresour. Technol. 213, 222-230 (2016).

4. Morgunov, I. G. \& Svetlana, V. K. Physiologo-biochemical characteristics of citrate-producing yeast Yarrowia lipolytica grown on glycerol-containing waste of biodiesel industry. Appl. Microbiol. Biotechnol. 99, 6443-6450 (2015).

5. Rakicka, M., Lazar, Z., Dulermo, T., Fickers, P. \& Nicaud, J. M. Lipid production by the oleaginous yeast Yarrowia lipolytica using industrial by-products under different culture conditions. Biotechnol. Biofuels 10.1186/S13068-015-0286-Z (2015).

6. Vivek, N. et al.Recent advances in the production of value added chemicals and lipids utilizing biodiesel industry generated crude glycerol as a substrate - Metabolic aspects, challenges and possibilities: An overview. Bioresour. Technol. 239, 507-517 (2017).

7. Chatzifragkou, A. \& Papanikolaou, S. Effect of impurities in biodiesel-derived waste glycerol on the performance and feasibility of biotechnological processes. Appl. Microbiol. Biotechnol. 95, 13-27 (2012).

8. Horan, N. J., Jarman, T.R. \& Dawes, E. A. Effects of carbon source and inorganic phosphate concentration on the production of alginic acid by a mutant of Azotobacter vinelandii and on the enzymes involved in its biosynthesis. Microbiology 127, 185-191 (1981).

9. Page, W. J. \& Von Tigerstrom, M. Induction of transformation competence in Azotobacter vinelandii iron-limited cultures. Can. J. Microbiol. 24, 1590-1594 (1978).

10. Noar, J.D. \& Bruno-Bárcena, J. M. Azotobacter vinelandii: The source of 100 years of discoveries and many more to come. Microbiology 164, 421-436 (2018).

11. Keshavarz, T. \& Roy, I. Polyhydroxyalkanoates: bioplastics with a green agenda. Curr. Opin. Microbiol. 13, 321-326 (2010).

12. Fialho, A. M., Zielinski, N. A., Fett, W. F., Chakrabarty, A. M. \& Berry, A. Distribution of alginate gene sequences in the Pseudomonas rRNA homology group I-Azomonas-Azotobacter lineage of superfamily B procaryotes. Appl. Environ. Microbiol. 56, 436-443 (1990).

13. Fischer, M. et al. Microbial alginate dressings show improved binding capacity for pathophysiological factors in chronic wounds compared to commercial alginate dressings of marine origin. J. Biomater. Appl. 31, 1267-1276 (2017).

14. Urtuvia, V., Maturana, N., Acevedo, F., Peña, C. \&Díaz-Barrera, A. Bacterial alginate production: an overview of its biosynthesis and potential industrial production. World J. Microbiol. Biotechnol. 10.1007/s11274-017-2363-x (2017). 
15. Yoneyama, F., Yamamoto, M., Hashimoto, W. \& Murata, K. Production of polyhydroxybutyrate and alginate from glycerol by Azotobacter vinelandii under nitrogen-free conditions. Bioengineered 6 , 209-217 (2015).

16. Ribeiro, P. L. L., da Silva, A. C. M. S., Filho, J. A. M. \& Druzian, J. I. Impact of different by-products from the biodiesel industry and bacterial strains on the production, composition, and properties of novel polyhydroxyalkanoates containing achiral building blocks. Ind. Crops Prod. 69, 212-223 (2015).

17. Cavalheiro, J. M. B. T., de Almeida, M. C. M. D., Grandfils, C. \& da Fonseca, M. M. R. Poly(3hydroxybutyrate) production by Cupriavidus necator using waste glycerol. Process Biochem. 44, 509-515 (2009).

18. Kenny, S. T. et al. Development of a bioprocess to convert PET derived terephthalic acid and biodiesel derived glycerol to medium chain length polyhydroxyalkanoate. Appl. Microbiol. Biotechnol. 95, 623633 (2012).

19. Naranjo, J. M., Posada, J. A., Higuita, J. C., Cardona, C. A. Valorization of glycerol through the production of biopolymers: The PHB case using Bacillus megaterium. Bioresour. Technol. 133, 3844 (2013).

20. Freches, A. \& Lemos, P. C. Microbial selection strategies for polyhydroxyalkanoates production from crude glycerol: Effect of OLR and cycle length. N. Biotechnol. 39, 22-28 (2017).

21. Mejía, M. Á., Segura, D., Espín, G., Galindo, E. \& Peña, C. Two-stage fermentation process for alginate production by Azotobacter vinelandii mutant altered in poly- $\beta$-hydroxybutyrate (PHB) synthesis. $J$. Appl. Microbiol. 108, 55-61 (2010).

22. Segura, D., Cruz, T., Espín, G. Encystment and alkylresorcinol production by Azotobacter vinelandii strains impaired in poly- $\beta$-hydroxybutyrate synthesis. Arch. Microbiol. 179, 437-443 (2003).

23. Stevenson, L. H. \& Socolofsky, M. D. Cyst formation and poly- $\beta$-hydroxybutyric acid accumulation in Azotobacter. J. Bacteriol. 91, 304-310 (1966).

24. Kreutz, F. H. Enzymatic glycerin determination. Klin. Wochenschr. 40, 362-363 (1962).

25. Sabra, W., Zeng, A. P. \& Deckwer, W. D. Bacterial alginate: physiology, product quality and process aspects. Appl. Microbiol. Biotechnol. 56, 315-325 (2001).

26. Knutson, C. A. \& Jeanes, A. A new modification of the carbazole analysis: Application to heteropolysaccharides. Anal. Biochem. 24, 470-481 (1968).

\section{Figures}

\section{Figure 1}


WG assimilation by $A$. vinelandii. (A) Growth of $A$. vinelandii wild-type and $\triangle$ algD cells on WG plate medium. The labels $(1 / 64,1 / 128$, and 1/256) in the left side represent the dilution fold. (B) Bacterial CFU (cells $/ \mathrm{ml}$ ) and residual glycerol concentration in 256-fold diluted WG medium. Circle and square represent $\mathrm{CFU}$ and glycerol concentration, respectively. (C) Bacterial CFU (cells/ml) (circle) and residual glycerol concentration (square) in 1/256-fold diluted WG-MB medium.
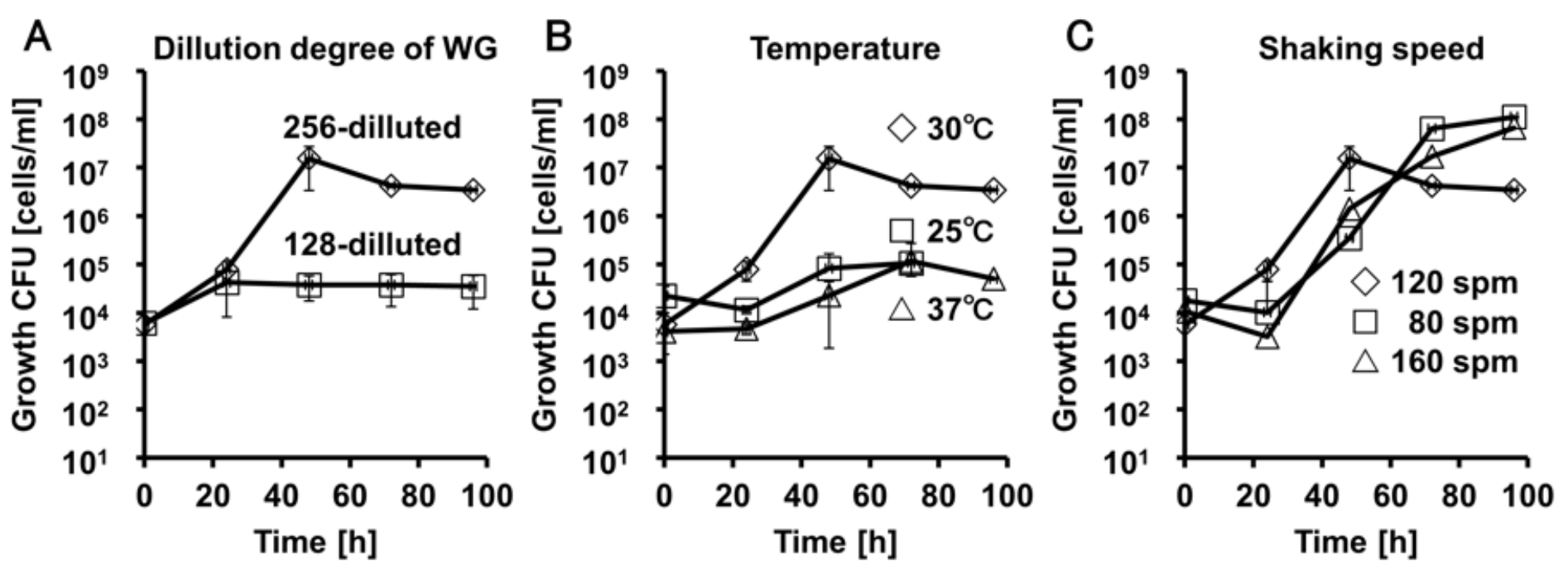

Figure 2

Investigation of culture conditions. (A) Effect of WG concentration on growth. Rhombus and square represent 1/256, and 1/128-fold dilution, respectively. (B) Effect of temperature on growth. Rhombus, square, and triangle represent 30,25 , and $37^{\circ} \mathrm{C}$, respectively. (C) Effect of shaking speed on growth. Rhombus, square, and triangle represent 120,80 , and 160 -spm, respectively.
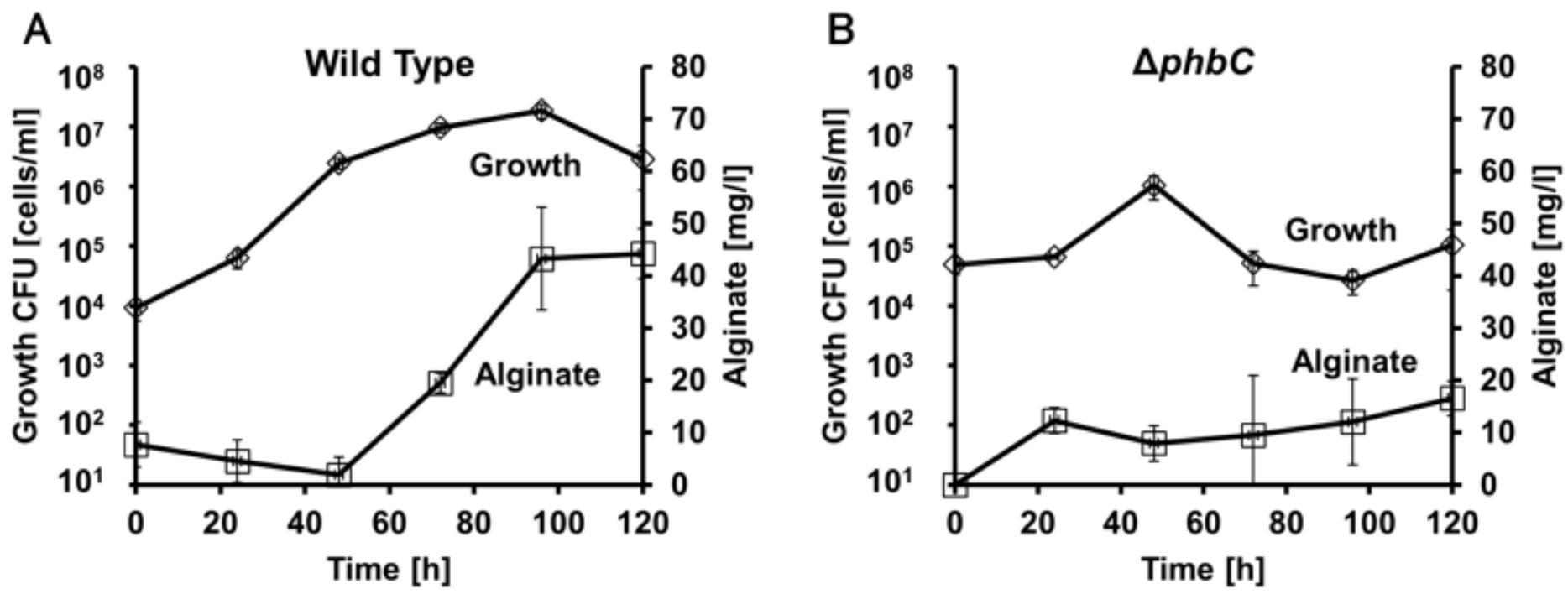

Figure 3 
Alginate production from WG. (A) Growth and alginate production (wild-type cells). Rhombus and square represent growth and alginate concentration, respectively. (B) Growth and alginate production (mutant $\triangle p h b C$ cells). Rhombus and square represent growth and alginate concentration, respectively.

\section{Figure 4}

PHB production from WG. (A) Growth and PHB production (wild-type cells). Rhombus and square represent growth and PHB concentration, respectively. (B) Growth and PHB production (mutant $\triangle a$ lgD cells). Rhombus and square indicate growth and PHB concentration, respectively. (C) PHB production per cell. At each time point, bar filled with a solid color and vertical lines represents wild-type and mutant $\triangle a l g D$ cells, respectively.

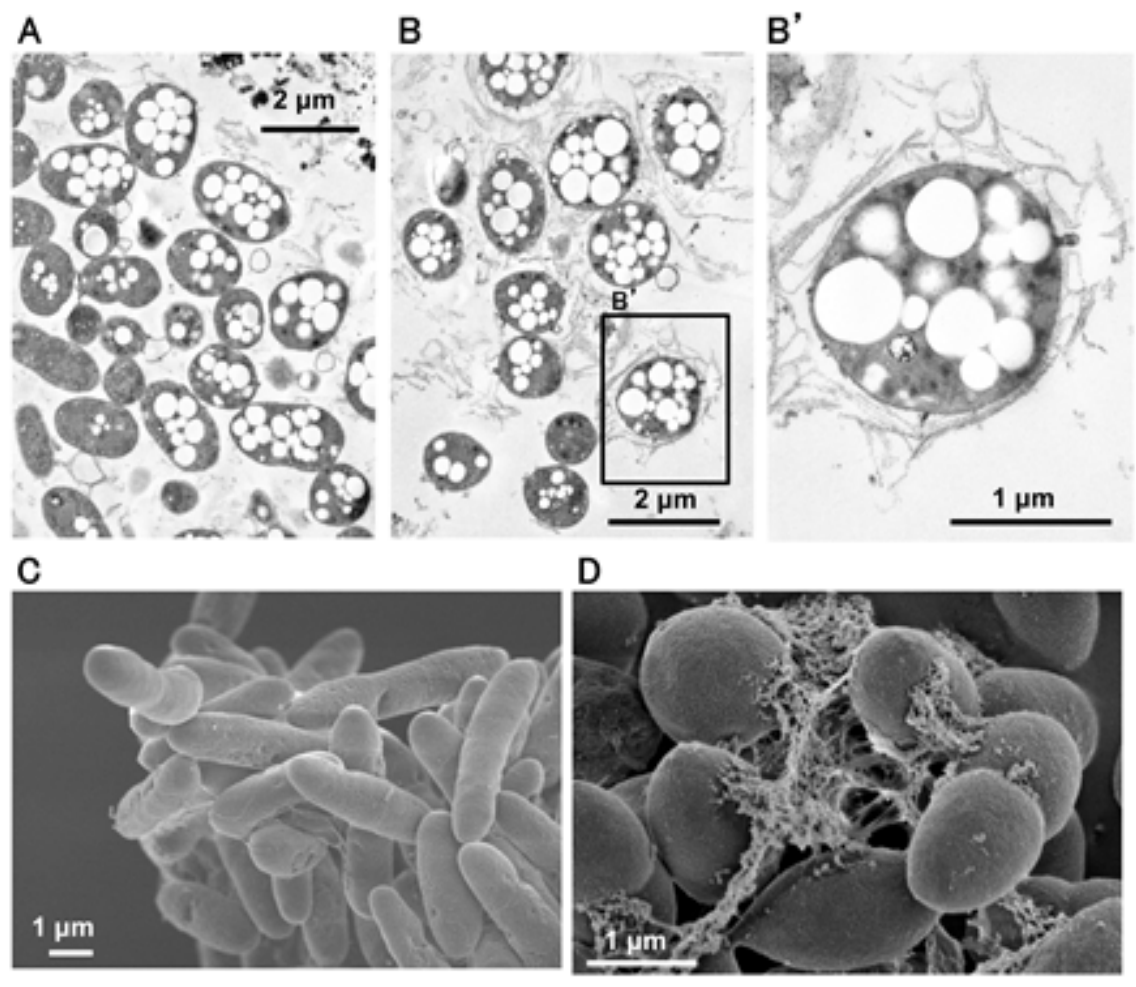

\section{Figure 5}

Electron microscopy images of $A$. vinelandii grown in a WG medium. (A, B, B') TEM images of cells cultured in WG-MB medium until the stationary growth phase (92 h). (C, D) SEM images of cell surface cultured in WG-MB medium [C: logarithmic growth phase (48 h), D: stationary phase (96 h)]. 


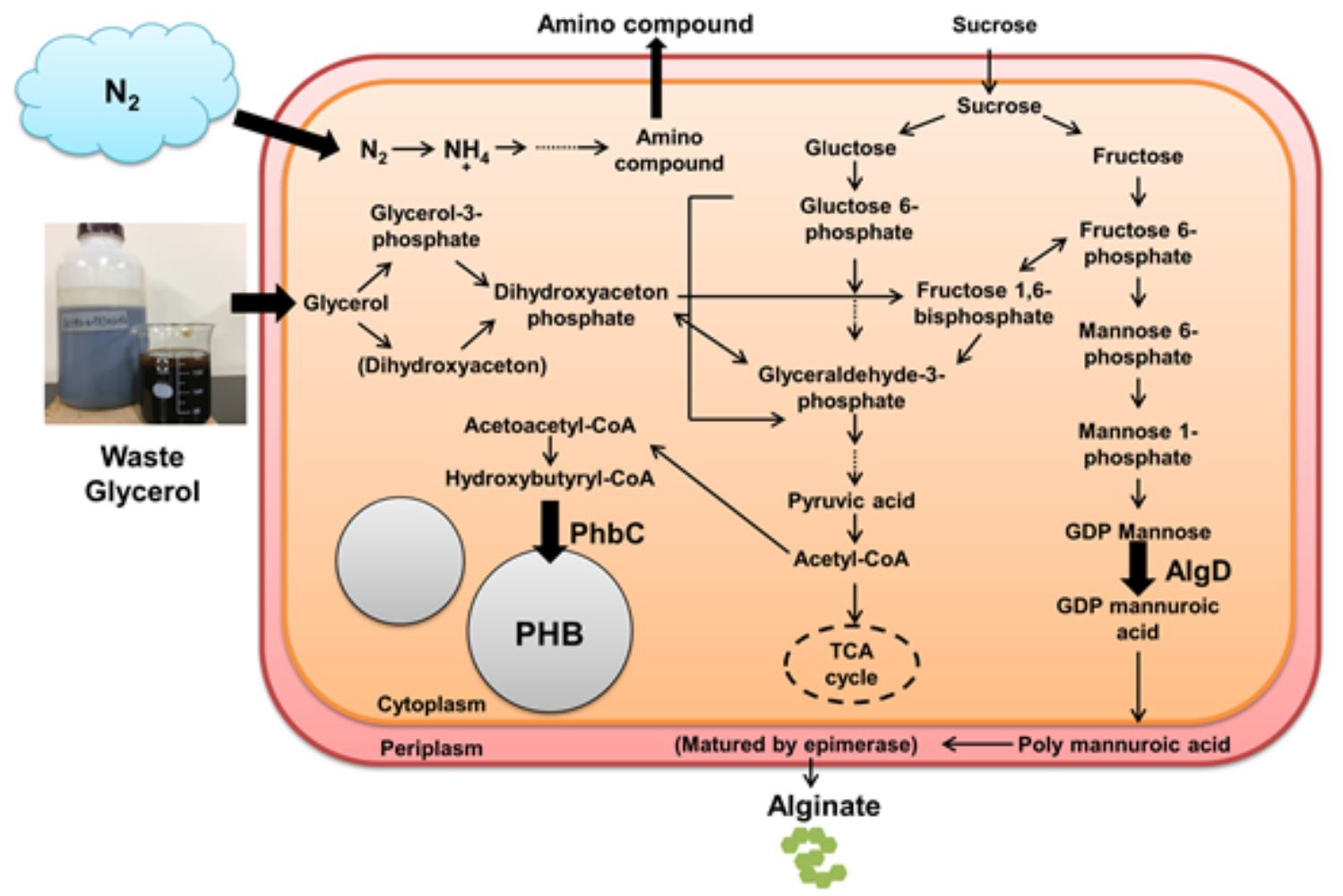

\section{Figure 6}

Model and metabolic map of WG recycling in $A$. vinelandii. 